\title{
Antiarrhythmic drugs for atrial fibrillation: Do we need better use, better drugs or a randomized trial of ablation as primary therapy?
}

\author{
Stanley Nattel
}

ß See related article page 741

A trial fibrillation (AF) is the most common cardiac arrhythmia seen in clinical practice, and it contributes substantially to both morbidity and medical costs. ${ }^{1}$ In this issue Humphries and associates present an analysis of antiarrhythmic drug therapy for AF based on the Canadian Registry of Atrial Fibrillation (CARAF) (see page 741). ${ }^{2}$ The authors consider the use of flecainide, quinidine, sotalol, amiodarone and propafenone, and they note that a large proportion of patients who received these antiarrhythmic drugs had conditions that constitute drug-related contraindications or warrant warnings and precautions. They suggest that the results point to a need for safer drugs, with fewer contraindications, precautions and warnings, with which to treat AF. A number of important factors need to be considered when we analyze the results of this interesting and significant study.

The CARAF trial enrolled patients whose AF was diagnosed between 1991 and 1996. The results presented by Humphries and associates were obtained at baseline and at 3 -month follow-up. Thus, most of the data reflect practices in use before 1996. The precautions, warnings and contraindications for the 5 antirrhythmic drugs studied are taken from the 1996 Compendium of Pharmaceuticals and Specialties (CPS), which was published after most treatment decisions had been made. Although most of the information might have applied in earlier versions of the CPS, this does not appear to have been assessed, which presents a limitation of the analysis.

The characteristics of the patient population also need to be considered. The study was limited to patients with paroxysmal $\mathrm{AF}$, for which heart-rate control is particularly difficult, ${ }^{3}$ making sinus-rhythm maintenance more often a primary objective. In addition, the vast majority of patients $(83 \%)$ were symptomatic at first presentation, which further justified the use of antiarrhythmic drugs to prevent $\mathrm{AF}$ recurrence. Given the decision to use an antiarrhythmic drug, an examination of the list of precautions, warnings and contraindications in Table 1 of the research article ${ }^{2}$ makes it clear that the results of the survey could hardly have been otherwise. For example, heart failure, a history of myocardial infarction and concomitant digoxin use are cautioned for all 5 drugs studied, and according to Table $2^{2}$ were present in 15\% (at baseline), 20\% (at baseline) and $46 \%$ (at 3 months) of the patient population respectively. The number of common conditions that are cautioned for each drug in Table 1 is so large that for many patients it was likely impossible to find any drug that did not involve a contraindication, warning or precaution. The authors recognize this and are careful to state that the use of antiarrhythmic agents may have reflected appropriate and judicious choices on the part of treating physicians. They note that a post hoc assessment of adverse events did not identify an association with medication use.

An additional and crucial point to consider is the changing context within which we view treatment of AF. Enrollment and data-gathering for the study by Humphries and associates were largely conducted between 1991 and 1996. The AFFIRM ${ }^{4}$ and RACE $^{5}$ studies published last year demonstrated equivalent outcomes for rate and rhythm control approaches and emphasized the risks of the use of antiarrhythmic drugs for rhythm control (e.g., proarrhythmia, drug-specific adverse effects, risk of thromboembolic stroke if oral anticoagulants stopped, etc.). Radiofrequency ablation approaches to managing $\mathrm{AF}$ emerged in the second half of the 1990s. The strategy of atrioventricular nodal ablation and permanent pacemaking was found to produce an excellent symptomatic result in patients who are refractory to drugs, particularly those with paroxysmal AF. ${ }^{6}$ More recently, the elaboration of effective ablation procedures directed toward the pulmonary vein region of the left atrium have resulted in apparent "cure" rates of > $80 \%{ }^{7,8}$ These major developments condition how we see the results of the study by Humphries and associates but obviously could not have affected physician judgement at the time that the CARAF data were being obtained. The real question, however, is not how we judge antiarrhythmic drug use in 1991-1996 by today's standards, but what the implications of this study are for current medical practice in light of our present knowledge and capabilities.

Physicians are obviously better equipped to make decisions about $\mathrm{AF}$ management today than they were in the early 1990s. In the light of AFFIRM and RACE, asymptomatic patients should rarely, if ever, receive antiarrhythmic drugs for sinus rhythm maintenance. It is very likely that the follow-up study to CARAF, CARAF II,' will show the 
expected tendency toward reduced antiarrhythmic drug usage in $\mathrm{AF}$.

In light of the great efficacy of nonpharmacological ablation-based therapies for $\mathrm{AF}^{6-8}$ one cannot help but wonder whether such invasive approaches should be situated earlier in the therapeutic decision tree for many patients. In fact, in view of the high reported cure rates for paroxysmal $\mathrm{AF}$ treated with catheter-based radiofrequency pulmonary vein isolation ablation, ${ }^{7,8}$ this is perhaps the time for a randomized trial of ablation versus standard medical therapy as a primary approach to symptomatic patients with recurrent paroxysmal AF.

Humphries and associates mention the potential interest of new and improved antiarrhythmic drugs for AF. Certainly, drugs with fewer contraindications and greater safety would be valuable. Targeting atrial-specific ion channels and developing antiarrhythmic drugs with selected channel-blocking profiles are very attractive approaches, ${ }^{9,10}$ but their practical value and applicability for $\mathrm{AF}$ have yet to be confirmed. Recent developments in understanding the pathophysiology of AF make targeting the AF substrate an interesting possibility. ${ }^{11,12}$ Success in preventing components of AF pathophysiology,,$^{13-16}$ including the prevention of $\mathrm{AF}$-promoting structural remodelling by suppressing renin-angiotensin activation, ${ }^{13,14}$ has been achieved in animal experiments. Clinical trials indicate the potential value of inhibiting angiotensin-converting enzyme $^{17-19}$ or blocking angiotensin type-1 receptors ${ }^{20}$ in preventing $\mathrm{AF}$ recurrence.

The study by Humphries and associates sensitizes us to the limitations inherent in choosing currently available antiarrhythmic drugs for AF therapy. It also points to the fact that our choices for AF therapy may be much more informed and richer in 2004 than they were in 1994. There is hope for drug therapy that targets the atria without risk of adverse effects on the ventricles and that prevents $\mathrm{AF}$ at the level of substrate development. A serious look needs to be taken at the possibility that ablation approaches may be better choices for many patients with $\mathrm{AF}$ than currently available antiarrhythmic agents. One can't help but think that the best way to take that look would be in the context of a well-designed prospective randomized clinical trial.

Dr. Nattel is Senior Scientist at the Research Center, Montreal Heart Institute, and Paul-David Chair in Cardiovascular Electrophysiology and Professor of Medicine at the University of Montreal, Montréal, Que. He is supported by the Canadian Institutes of Health Research, Quebec Heart Foundation and Paul-David Chair in Cardiovascular Electrophysiology, University of Montreal.

Competing interests: None declared.

\section{References}

1. Stewart S, Murphy N, Walker A, McGuire A, McMurray JJ. Cost of an emerging epidemic: an economic analysis of atrial fibrillation in the UK Heart 2004;90:286-92.

2. Humphries KH, Kerr CR, Steinbuch M, Dorian P, for the Canadian Registry of Atrial Fibrillation (CARAF) Investigators. Limitations to antiarrhythmic drug use in patients with atrial fibrillation. CMA7 2004;171(7):741-5.

3. Nattel S, Ehrlich JR. Chapter 56. Atrial Fibrillation. In: Zipes DP, Jalife J, editors. Cardiac electrophysiology, from cell to bedside. 4th ed. Philadelphia: W.B. Saunders; 2004. p. 512-23.

4. Wyse DG, Waldo AL, DiMarco JP, Domanski MJ, Rosenberg Y, Schron EB, et al. Atrial Fibrillation Follow-up Investigation of Rhythm Management (AFFIRM) Investigators: a comparison of rate control and rhythm control in patients with atrial fibrillation. N Engl f Med 2002;347:1825-33.

5. Van Gelder IC, Hagens VE, Bosker HA, Kingma JH, Kamp O, Kingma T, et al. Rate Control versus Electrical Cardioversion for Persistent Atrial Fibrillation Study Group: a comparison of rate control and rhythm control in patients with recurrent persistent atrial fibrillation. N Engl f Med 2002;347:1834-40.

6. Wood MA, Brown-Mahoney C, Kay GN, Ellenbogen KA. Clinical outcomes after ablation and pacing therapy for atrial fibrillation : a meta-analysis. Circulation 2000;101:1138-44.

7. Pappone C, Oreto G, Rosanio S, Vicedomini G, Tocchi M, Gugliotta F, et al. Atrial electroanatomic remodeling after circumferential radiofrequency pulmonary vein ablation: efficacy of an anatomic approach in a large cohort of patients with atrial fibrillation. Circulation 2001;104:2539-44.

8. Oral H, Scharf C, Chugh A, Hall B, Cheung P, Good E, et al. Catheter ablation for paroxysmal atrial fibrillation: segmental pulmonary vein ostial ablation versus left atrial ablation. Circulation 2003;108:2355-60.

9. Nattel S, Yue L, Wang Z. Cardiac ultrarapid delayed rectifiers: a novel potassium current family of functional similarity and molecular diversity. Cell Physiol Biochem 1999;9:217-26.

10. Nattel S. The molecular and ionic specificity of antiarrhythmic drug actions. f Cardiovasc Electrophysiol 1999;10:272-82.

11. Nattel S. Therapeutic implications of atrial fibrillation mechanisms: can mechanistic insights be used to improve AF management? Cardiovasc Res 2002;54:347-60.

12. Allessie M, Ausma J, Schotten U. Electrical, contractile and structural remodeling during atrial fibrillation. Cardiovasc Res 2002;54:230-46.

13. Li D, Shinagawa K, Pang L, Leung TK, Cardin S, Wang Z, et al. Effects of angiotensin-converting enzyme inhibition on the development of the atrial fibrillation substrate in dogs with ventricular tachypacing-induced congestive heart failure. Circulation 2001;104:2608-14.

14. Kumagai K, Nakashima H, Urata H, Gondo N, Arakawa K, Saku K. Effects of angiotensin II type 1 receptor antagonist on electrical and structural remodeling in atrial fibrillation. 7 Am Coll Cardiol 2003;41:2197-204.

15. Fareh S, Benardeau A, Thibault B, Nattel S. The T-type $\mathrm{Ca}(2+)$ channel blocker mibefradil prevents the development of a substrate for atrial fibrillation by tachycardia-induced atrial remodeling in dogs. Circulation 1999;100:2191-7.

16. Shinagawa K, Shiroshita-Takeshita A, Schram G, Nattel S. Effects of antiarrhythmic drugs on fibrillation in the remodeled atrium: insights into the mechanism of the superior efficacy of amiodarone. Circulation 2003;107:1440-6.

17. Pedersen OD, Bagger H, Kober L, Torp-Pedersen C. Trandolapril reduces the incidence of atrial fibrillation after acute myocardial infarction in patients with left ventricular dysfunction. Circulation 1999;100:376-80.

18. Vermes E, Tardif JC, Bourassa MG, Racine N, Levesque S, White M, et al. Enalapril decreases the incidence of atrial fibrillation in patients with left ventricular dysfunction: insight from the Studies Of Left Ventricular Dysfunction (SOLVD) trials. Circulation 2003;107:2926-31.

19. Ueng KC, Tsai TP, Yu WC, Tsai CF, Lin MC, Chan KC, et al. Use of enalapril to facilitate sinus rhythm maintenance after external cardioversion of long-standing persistent atrial fibrillation. Results of a prospective and controlled study. Eur Heart 7 2003;24:2090-8.

20. Madrid AH, Bueno MG, Rebollo JM, Marin I, Pena G, Bernal E, et al. Use of irbesartan to maintain sinus rhythm in patients with long-lasting persistent atrial fibrillation: a prospective and randomized study. Circulation 2002;106:331-6.

Correspondence to: Dr. Stanley Nattel, Montreal Heart Institute Research Center, 5000 Belanger St. E., Montréal QC H1T 1C8; fax 514 376-1355; Stanley.nattel@icm-mhi.org 